\title{
Estimation of the Proportion of Offspring Having Genetically Crispy Flesh in Grape Breeding
}

\author{
Akihiko Sato', Masahiko Yamada, and Hiroshi Iwanami2 \\ Department of Grape and Persimmon Research, National Institute of Fruit Tree Science. Higashi \\ Hiroshima, Hiroshima 729-2494, Japan
}

\begin{abstract}
Additional index words. Vitis spp., flesh texture, genetic analysis, statistical genetics, puncture test
Abstract. Berry texture of grapes (Vitis labruscana Bailey, $V$. vinifera L., and their hybrids) can be characterized by two factors: 1) difficulty of breakdown in mastication and 2) firmness, which can be mechanically measured as deformation at first major peak (DFP) and maximum force (MF) of the force-deformation curve in flesh puncture tests. Crisp texture (easily breakable and firm flesh texture), one of the most important factors for the quality of table grapes, corresponds to a combination of small DFP $(\leq 2.5 \mathrm{~mm})$ and large MF $(\geq 0.9 \mathrm{~N})$. Obtaining offspring with crispy flesh is a primary objective in grape interspecific hybrid breeding at the National Institute of Fruit Tree Science, Japan. In this study, the expected proportion (EP) of offspring with crispy flesh as a genotypic value was estimated using a population consisting of $\mathbf{2 3}$ full-sib families each with eight offspring. An analysis of variance in the offspring, which estimated between-family and within-family variances, and the regression analysis of the family mean (Fm) of eight offspring in each full-sib family on mid-parental value (MP) were conducted for DFP and MF. The results revealed that the total genetic variation in offspring was mostly explained by the variance due to the regression and the within-family variance for both DFP and MF. No significant heterogeneity of within-family variance was detected by Bartlett's test for either DFP or MF. Therefore, a simple model was used to calculate EP: Fm is solely determined by the regression of Fm on MP, and all families have an equal within-family genetic variance due to segregation. Since merely a weak correlation relationship existed between DFP and MF, its influence was omitted in calculating EP. The EP of offspring having crisp texture was estimated to be $11 \%$ for an MP value of DFP of $2.5 \mathrm{~mm}$ (DFP for 'Italia'), $6 \%$ for a DFP of $3.5 \mathrm{~mm}$ (DFP for 'Athens'), and 3\% for a DFP of $4.5 \mathrm{~mm}$ (DFP for 'Bath'); the MP value of MF was assumed to be 0.7 $\mathbf{N}$ (MF for 'Steuben' and 'Italia') in this calculation.
\end{abstract}

Grape (Vitis L.) is the most important fruit crop in the world, grown on over 9 million hectares (Alleweldt et al., 1990; Reisch and Pratt, 1996). The leading cultivars are European grapes ( $V$. vinifera) (Alleweldt and Possingham, 1988; Alleweldt et al., 1990), which account for more than $90 \%$ of the world production (Winkler, 1962). This species includes table-use cultivars producing large berries of high quality. However, it requires a warm and dry climate (Hedrick, 1925) and is highly susceptible to fungal diseases such as downy mildew [Plasmopara viticola (Berkeley et Curtis) Berlese et de Toni] and anthracnose [Elsinoe ampelina (de Bary) Shear] (Winkler, 1962). The failure of early colonists to establish $V$. vinifera in eastern North America was due to the species' lack of resistance to native diseases, soil pests, and low winter temperatures in the northernmost areas (Einset and Pratt, 1975). Therefore, interspecific hybrid cultivars which perform better in northern regions have been developed by crossing $V$. vinifera grapes and native species of the United States. The most commonly used native species was the fox grape (V. labrusca L.), and interspecific hybrid cultivars showing $V$. labrusca characteristics are classified as V. labruscana (Bailey and Bailey, 1930).

There is a large difference in berry texture between $V$. vinifera and V. labruscana (Galet, 1979; Hedrick, 1925). The flesh of $V$. vinifera breaks down easily when chewed, whereas $V$. labruscana is difficult to masticate (Bourne, 1979) and forms a gelatinous mass (Galet, 1979). The firm and easily chewed flesh of V. vinifera

\footnotetext{
Received for publication 11 May 2005. Accepted for publication 4 Aug. 2005. 'Present address: National Institute of Fruit Tree Science, Tsukuba, Ibaraki 3058605, Japan. To whom reprint requests should be addressed. E-mail address: satoaki@affrc.go.jp

${ }^{2}$ Present address: Dept. of Apple Research, National Institute of Fruit Tree Science, Morioka, Iwate 020-0123, Japan.
}

cultivars is termed "crisp," a highly desirable character in table grapes. In contrast, the texture of V. labruscana is considered responsible for the limited consumption of $V$. labruscana as a fresh fruit (Bourne, 1979).

To characterize the texture of food products, various instruments, such as the Texturometer (Friedman et al., 1963) and the Instron Universal Testing Machine (Bourne and Mondy, 1967), have been developed. Mechanically measured variables most often used to define textural characteristics are force and deformation (distance) (Bourne, 1966), and several related variables have been determined in apple (Malus xdomestica Borkh.) from force-deformation diagrams using the Instron Universal Testing Machine (Abbott et al., 1984). The texture and firmness of various fruit crops was puncture- and compression-tested by the same machine (Abbott et al., 1984; Brown, 1968; Lee and Bourne, 1980).

Sato et al. (1997) studied berry texture instrumentally with a flesh puncture test using a rheometer (an Instron-type machine). They showed that the degree of difficulty of breakdown in mastication and flesh firmness could be expressed as deformation at DFP and MF, respectively, in the force-deformation curve, because of the high correlation between the measured values and the results of sensory tests. According to Sato et al. (1997), V. vinifera cultivars showed a small DFP and a wide variation of MF in the test. These properties related with descriptive sensory terms such as "firm," "crisp," and "melting," used in the literature (Galet, 1979; Hedrick, 1925; Weinberger and Harmon, 1974).

Vitis labruscana grapes, on the other hand, exhibited wide variation in both DFP and MF (Sato and Yamada, 2003; Sato et al., 1997). The texture of V. labruscana grapes was described as "tough" or "tender" (Hedrick, 1925; Slate et al., 1962). The puncture tests suggested that the term "tough" was used to describe flesh with large DFP and MF, while the term "tender" was 
preferentially assigned to flesh with small to medium DFP and MF (Sato et al., 1997). No V. labruscana cultivars were classified as "crisp" due to the positive correlation between DFP and MF (Sato and Yamada, 2003; Sato et al., 1997).

Because of heavy rainfall during the growing season, Japanese grape farmers have primarily grown interspesific hybrid cultivars. However, almost no hybrid cultivars in Japan so far has fully met the high expectations of Japanese consumers regarding high eating quality. The National Institute of Fruit Tree Science (NIFTS) has conducted breeding programs for more than 30 years to create grape cultivars with excellent eating quality, large berries, disease resistance, and a high degree of cold hardiness. So far, the NIFTS released five new diploid cultivars that were selected from crosses of $V$. vinifera, V. labruscana, and their hybrids (Yamada et al., 2004, 2005; Yamane et al., 1988, 1991, 1992). However, no studies on the genetics of flesh texture have been reported yet. Therefore, it has been unknown whether interspecific crosses can yield offspring with crispy flesh or not.

The proportion of offspring having genotypic values exceeding a critical value in selection is the most important information for fruit breeders. A method for predicting the expected proportion (EP) was established by Yamada et al. $(1994,1995,1997)$ and Yamada and Yamane (1997). The objective of this study was to estimate the expected proportion of offspring having crispy flesh in interspecific hybrid breeding by quantitating flesh texture instrumentally.

\section{Materials and Methods}

The POPUlation. This study was carried out using offspring from the table grape breeding program at NIFTS. Nine cultivars/ selections of $V$. vinifera. and eight interspecific hybrids were used as parents (Table 1). All parents were diploid. The interspecific hybrid selections resulted from crosses among V. labruscana and

Table 1. Deformation at first major peak (DFP) and maximum force (MF) from flesh puncture test for grape cultivars/selections used as cross-parents.

\begin{tabular}{llcc}
\hline Species & \multicolumn{1}{c}{$\begin{array}{c}\text { Cultivars/ } \\
\text { selections }\end{array}$} & $\begin{array}{c}\text { DFP } \\
(\mathrm{mm})\end{array}$ & $\begin{array}{r}\text { MF } \\
(\mathrm{N})\end{array}$ \\
\hline Vitis vinifera & Alphonse Lavallee & $1.94 \mathrm{z}$ & $0.59^{\mathrm{z}}$ \\
& Italia & 1.79 & 0.54 \\
& July Muscat & 2.32 & 0.89 \\
& Katta Kurgan & 2.07 & 0.75 \\
& Madereine Celine & 1.87 & 0.67 \\
& Rizamat & 1.79 & 0.93 \\
& Rosaki & 2.06 & 0.78 \\
& Sekirei & 2.29 & 0.63 \\
Interspecific hybrid & Alden & 1.98 & 0.78 \\
& Akitsu 7 & 2.38 & 0.55 \\
& Akitsu 21 & 5.39 & 1.02 \\
& Baffalo & 2.69 & 1.10 \\
& North Red & 6.28 & 1.06 \\
& Seneca & 5.00 & 0.45 \\
& 85 - 62 & 2.07 & 0.62 \\
& 103 - 37 & 3.03 & 0.50 \\
\end{tabular}

${ }^{\mathrm{z}}$ Mean value of four berries in each of five clusters on a single vine for 3 years. $105-54=$ an $F_{1}$ of 'Neo Muscat' $x$ 'Cardinal', Akitsu $7=$ an $\mathrm{F}_{1}$ of 'Takasago' $\mathrm{x}$ 'Campbell Early', Akitsu $21=$ an $\mathrm{F}_{1}$ of 'Steuben' $\mathrm{X}$ 'Muscat of Alexandria', $85-62=$ an $F_{1}$ of 'Steuben' $x$ 'Rizamat', 103$37=$ an $F_{1}$ of 'Katta Kurgan' $x$ 'Takasago'.
V. vinifera cultivars. The offspring population (184 individuals) consisted of 23 full-sib families each with eight offspring (Table 2). The crosses were made solely for the purpose of genetic improvement without a specific mating design. Seedlings initially were grown in a greenhouse. One shoot was taken from each seedling and was grafted onto a 'Kober $5 \mathrm{BB}$ ' rootstock. These plants were planted in the vineyard with $0.6 \times 3.2-\mathrm{m}$ spacing.

Textural evaluation. A flesh puncture test was performed on the berries from parents and offspring harvested at their respective ripening time. In the test, deformation at first major peak (DFP, distance from sample surface to first rupture) and maximum force (MF) were measured using a rheometer (model NRM 2010J-CW; Fudoh, Tokyo) according to Sato et al. (1997). A flesh section of 8-mm thickness was cut longitudinally from each berry. The sample was mounted on the stage of the rheometer which had a 4-mm-diameter hole. A plunger with $3 \mathrm{~mm}$ diameter was used at a puncturing rate of $50 \mathrm{~mm} \cdot \mathrm{min}^{-1}$. Force of compression and distance from the surface of the sample were recorded as a forcedeformation curve, from which DFP and MF were determined. Five berries from one cluster of each offspring were analyzed in the first fruiting year without annual repetition, while five berries each from four clusters from one vine of each parent were evaluated with three annual repetitions.

ESTIMATION OF THE GENETIC PARAMETERS FOR DEFORMATION AT FIRST MAJOR PEAK AND MAXIMUM FORCE. The data were transformed logarithmically to improve the normality of the distribution. Family mean (Fm) was calculated as the mean value of eight offspring vines in each full-sib family. Regression analysis was carried out with Fm as the dependent variable and the mid-parental value (MP) as the independent variable. According to the model by Yamada et al. (1997), the performance of DFP and MF of the jth offspring in the ith family is given by $\mathrm{Y}_{\mathrm{ij}}$ :

$$
\mathrm{Y}_{\mathrm{ij}}=\mu+\beta \mathrm{x}_{\mathrm{i}}+\mathrm{d}_{\mathrm{i}}+\mathrm{w}_{\mathrm{ij}}
$$

where $\mu=$ overall mean across offspring and families

$\mathrm{x}_{\mathrm{i}}=$ deviation of MP of the ith family from the overall mean

$\beta=$ coefficient of regression of the family mean on MP

$\mathrm{d}_{\mathrm{i}}=$ deviation of the family mean from the regression

$\mathrm{w}_{\mathrm{ij}}=$ within-family deviation contributed by genetic and environmental effects in the jth offspring of the ith family.

The deviation of each family mean from the regression $\left(\mathrm{d}_{\mathrm{i}}\right)$ and the deviation of each offspring from the family mean $\left(\mathrm{w}_{\mathrm{ij}}\right)$ were tested for normality of the distribution by Kolmogorov-Smirnov's one sample test (Campbell, 1974); both were approached to be normally distributed around each family mean. The homogeneity of within-family variances was tested by Bartlett's test (Snedecor

Table 2. Crossing combinations of parental grape cultivars/selections in 23 full-sib families used in this study.

\begin{tabular}{ll}
\hline Cross combination & Cross combination \\
\hline Alphonse Lavallee x Alden & North Red x Akitsu 7 \\
Alphonse Lavallee x July Muscat & North Red x Buffalo \\
Alphonse Lavallee x Rizamat & North Red x Madeleine Celine \\
Alden x Rizamat & North Red x Rosaki \\
Akitsu 21 x Alden & Rizamat x Sekirei \\
Italia x Alden & Seneca x Akitsu 7 \\
Italia x North Red & $85-62$ x Alden \\
Italia x Rizamat & $85-62 \times$ Alphonse Lavallee \\
July Muscat x North Red & $85-62 \times$ Italia, \\
July Muscat x Seneca & $103-37 \times$ Akitsu 7 \\
Katta Kurgan x North Red & $105-54$ x Alden \\
Madeleine Celine x Buffalo & \\
\hline
\end{tabular}


and Cochran, 1972). No significant heterogeneity was detected at $P=0.05$ for either DFP or MF. Therefore, offspring in each family were assumed to distribute normally around the family mean estimated by the regression line, with within-family variance.

A one-way analysis of variance (ANOVA) for the data of each offspring was performed to estimate between-family variance $\left(\sigma^{2}{ }_{b f}\right)$ and within-family variance $\left(\sigma^{2}{ }_{w}\right)$ (Table 3$) . \sigma^{2}{ }_{w}$ consists of genetic $\left(\sigma^{2}{ }_{w g}\right)$ and environmental variance $\left(\sigma^{2}{ }_{w e}\right)$. According to Yamada et al. $(1993,1994,1995,1997)$ and Yamada and Yamane (1997), $\sigma^{2}{ }_{w g}$ was calculated by subtracting $\sigma^{2}{ }_{w e}$ from $\sigma^{2}{ }_{w} . \sigma^{2}{ }_{w e}$ was assumed to be the environmental variance in five berries in a cluster on a single vine measured in 1 year. According to Sato et al. (2000), the environmental variance of the mean performance in offspring $\left(\sigma^{2}{ }_{w e}\right)$ is $\sigma^{2}{ }_{w e}=\sigma^{2}{ }_{b} / y v c b+\sigma^{2}{ }_{c} / y v c+\sigma^{2} / v+\sigma_{v}{ }_{v y} / y v$ $+\sigma^{2}{ }_{\mathrm{gy}} / \mathrm{y}+\sigma_{\mathrm{y}}^{2} / \mathrm{y}$, where $\sigma_{\mathrm{b}}^{2}$ is the variance among berries within clusters, $\sigma_{c}^{2}$ is the variance among clusters within vines, $\sigma^{2}$ is the variance among vines within genotypes, $\sigma^{2}{ }_{v y}$ is the variance due to interaction between vine and year, $\sigma_{\mathrm{gy}}^{2}$ is the variance due to interaction between genotype and year, $\sigma^{2}$ is the variance among years, $y$ is the number of years repeated, $v$ is the number of vines per genotype, $\mathrm{c}$ is the number of clusters per vine, and $\mathrm{b}$ is the number of berries per cluster. Estimates of environmental variance components have been obtained previously (Sato et al., 2000). Here, $\sigma^{2}{ }_{\text {we }}$ was estimated as $\sigma_{b}^{2} / 5+\sigma^{2}{ }_{c}+\sigma^{2}{ }_{v}+\sigma^{2}{ }_{v y}+\sigma^{2}{ }_{g y}+$ $\sigma_{\mathrm{y}}^{2}(\mathrm{~b}=5, \mathrm{c}=1, \mathrm{v}=1$, and $\mathrm{y}=1)$. The environmental variance of the mid-parental value $\left(\sigma_{\text {MPE }}^{2}\right)$ was also estimated as $\left(\sigma^{2}{ }_{b} / 60\right.$ $\left.+\sigma^{2}{ }_{\mathrm{c}} / 12+\sigma_{\mathrm{v}}^{2}+\sigma_{\mathrm{vy}}^{2} / 3+\sigma_{\mathrm{gy}}^{2} / 3+\sigma_{\mathrm{y}}^{2} / 3\right) / 2(\mathrm{~b}=5, \mathrm{c}=4, \mathrm{v}=1$, and $\mathrm{y}=3$ ). Here, the environmental variance among mid-parents is half of the variance among individual parents.

ESTIMATION OF THE EXPECTED PROPORTION OF OFFSPRING HAVING GENETICALLY CRISP TEXTURE. The expected proportion of offspring having genotypic values was calculated based on a normal density function. As shown in the Results section, the variance due to $d_{i}$ was so small for both DFP and MF that it could be omitted in estimating EP. Therefore, EP was calculated using a model in which the genotypic value of offspring was distributed as shown in Fig. 1. True mean value within a family, $\operatorname{Fm}(n=\infty)$, that is, family-mean with no error due to the number of offspring within the family, were estimated by the regression of the family-mean under eight offspring on MP. The Fm $(n=\infty)$ is the estimate of the family mean as a genetic value with no error due to the number of offspring within the family. Each offspring's genotypic value in a family was assumed to be distributed around Fm $(n=\infty)$ with the within-family genetic variance, $\sigma^{2}{ }_{w g}$.

Table 3. Expected mean squares of analysis of variance and regression analysis using 23 full-sib families each with eight offspring in grapes.

\begin{tabular}{lrl}
\hline $\begin{array}{l}\text { Source of } \\
\text { variation }\end{array}$ & \multicolumn{1}{c}{ df } & \multicolumn{1}{c}{ Expected mean squares } \\
\hline Between-family & 22 & $\sigma^{2}{ }_{\mathrm{w}}+8 \sigma_{\mathrm{d}}^{2}+8 \sigma_{\mathrm{r}}^{2}=\sigma^{2}{ }_{\mathrm{w}}+8 \sigma^{2}{ }_{\mathrm{bf}}$ \\
Regression & 1 & $\sigma^{2}{ }_{\mathrm{w}}+8 \sigma^{2}{ }_{\mathrm{d}}+176 \sigma_{\mathrm{r}}^{2}$ \\
Residual & 21 & $\sigma^{2}+8 \sigma^{2}{ }_{\mathrm{d}}$ \\
Within-family & 161 & $\sigma^{2}{ }_{\mathrm{w}}$ \\
Total & 183 &
\end{tabular}

${ }^{2}$ Regression of family mean on mid-parental value. $\sigma^{2}{ }_{w}=$ within-family variance. $\sigma_{d}^{2}=$ variance component associated with the residual from the regression. $\sigma_{\mathrm{r}}^{2}=$ variance component associated with the regression. $\sigma^{2}{ }_{b f}=$ between-family variance $=\sigma_{r}^{2}+\sigma_{d}^{2}$.

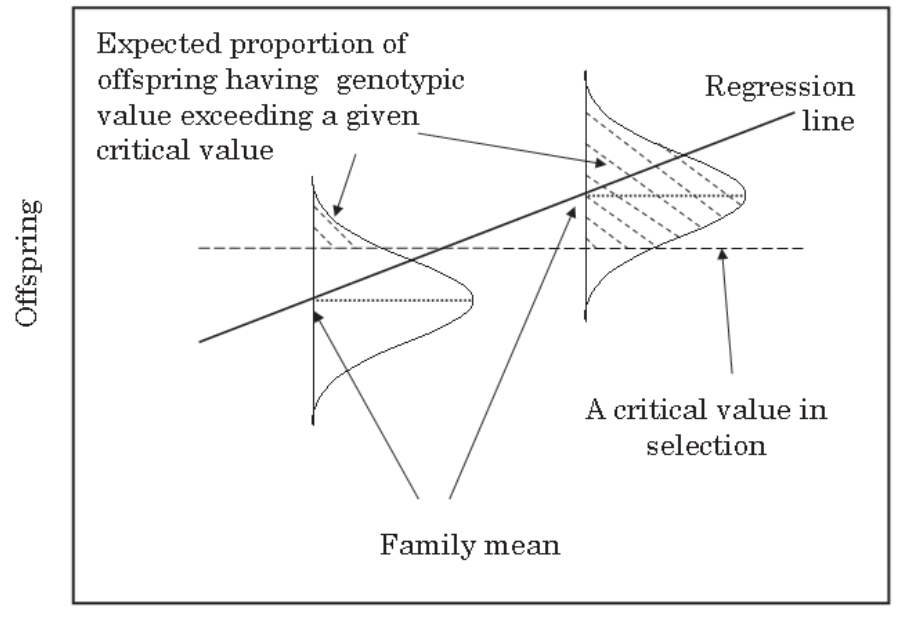

Mid-parent

Fig. 1. Model diagram in calculating an expected proportion of offspring having genotypic values exceeding a critical value for maximum force from flesh puncture test in grapes. The proportion is expressed as the area exceeding a critical value. Conversely, the proportion for deformation at first major peak is expressed as that of portion below a critical value.

The expected proportion (EP) of offspring below a critical value $\left(s_{1}\right)$ of DFP was:

$\operatorname{EP}\left[\mathrm{z}_{1} \leq \log \left(\mathrm{s}_{1}\right)\right]=\frac{1}{\sqrt{2 \pi} \sigma_{w g}} \int_{-\infty}^{\log \left(s_{1}\right)} \exp ^{u} d z_{1}$

$\mathrm{u}=-\left(\mathrm{z}_{1}-\mathrm{Fm}_{1}\right)^{2} /\left(2 \sigma_{\mathrm{wg}}^{2}\right)$,

where $\mathrm{Fm}_{1}$ is $\mathrm{Fm}(\mathrm{n}=\infty)$ for DFP.

On the other hand, the expected proportion of offspring exceeding a critical value $\left(\mathrm{s}_{2}\right)$ of MF was:

$\mathrm{EP}\left[\mathrm{z}_{2} \geq \log \left(\mathrm{s}_{2}\right)\right]=\frac{1}{\sqrt{2 \pi} \sigma_{w g}} \int_{\log \left(s_{2}\right)}^{\infty} \exp ^{u} d z_{2}$

$\mathrm{u}=-\left(\mathrm{z}_{2}-\mathrm{Fm}_{2}\right)^{2} /\left(2 \sigma_{\mathrm{wg}}^{2}\right)$,

where $\mathrm{Fm}_{2}$ is $\mathrm{Fm}(\mathrm{n}=\infty)$ for MF.

Previous reports (Sato et al., 1997; Sato and Yamada, 2003) showed that DFP in V. labruscana, which consists mostly of interspecific hybrids, was larger than in $V$. vinifera, although there was nearly the same variation in MF in both species. Moreover, MF in $V$. labruscana was positively correlated to DFP, whereas in $V$. vinifera it was not. In the present study, however, the coefficient of determination $\left(r^{2}\right)$ between DFP and MF was 0.05 for the whole offspring population. The very low correlation in the present study may be due to the fact that the offspring population was mainly derived from backcrosses of interspecific hybrids to $V$. vinifera cultivars/selections and crosses among $V$. vinifera.

As the correlation between DFP and MF was week in our data, the two variables were assumed independent of each other for simplification in estimating the expected proportion of offspring having crisp texture. Since crisp texture corresponds to a combination of DFP $(\leq 2.5 \mathrm{~mm})$ and $\mathrm{MF}(\geq 0.9 \mathrm{~N})$, the expected proportion of offspring having genetically crisp texture in a family was estimated as $\operatorname{EP}\left[z_{1} \leq \log (2.5)\right] \times \operatorname{EP}\left[z_{2} \geq \log (0.9)\right]$. 


\section{Results}

AnAlysis of Deformation at FIRST MAJOR PEAK. The mean value of DFP was nearly identical in MP [0.4312 $(\log 2.70 \mathrm{~mm})]$ and parental mean $[0.4017(\log 2.52 \mathrm{~mm})]$ (Table 4). The variance of DFP in MP(0.0172) was about half of that in the parental group. These results suggested that crosses were made randomly within the parental cultivars/selections. The genetic variance of $\operatorname{MP}\left(\sigma_{\text {MPG }}^{2}\right)$, which was obtained by subtracting $\sigma^{2}{ }_{\text {MPE }}(0.0006)$ from the phenotypic variance of $\mathrm{MP}\left[\sigma^{2}{ }_{\mathrm{MPP}}(0.0172)\right]$, was 0.0166 . The ratio $\sigma^{2}{ }_{M P G} / \sigma^{2}{ }_{\text {MPP }}$ was 0.97 , indicating that MP was highly heritable. The overall mean DFP of the offspring was 0.3401 (log $2.19 \mathrm{~mm}$ ), which was near that of MP.

ANOVA revealed that the regression of Fm on MP was highly significant (Table 5). The between-family variance $\left(\sigma_{b f}^{2}\right)$ consisted mostly of the variance associated with the regression $\left(\sigma_{r}^{2}\right)$, which accounted for $91 \%$ of the $\sigma_{\text {bf }}^{2}$ (Table 6 ). This result indicated that the genetic variation among families was mostly explained by the MP value. The regression equation obtained was $\mathrm{Fm}=0.781$ $\mathrm{MP}+0.003$ (Fig. 2A). The SE of the regression coefficient was $\pm 0.098 . \sigma_{\text {wg }}^{2}$ was estimated at 0.0152 .

Based on these estimates, the expected proportions (EP) of offspring having genotypic values below a critical value were calculated based on parental measurements of five berries each from four clusters on a single vine for 3 years (Fig. 3A). The EP of offspring having DFPs smaller than $2.5 \mathrm{~mm}$ decreased as the mid-parental values increased. It was $75 \%$ for $\mathrm{MP}=2.5 \mathrm{~mm}$, $40 \%$ for $3.5 \mathrm{~mm}$, and $18 \%$ for $4.5 \mathrm{~mm}$.

AnAlysis OF MAXIMUM FORCE. MF had similar mean values in MP $(0.65 \mathrm{~N})$ and in the parents $(0.72 \mathrm{~N})$ (Table 4). Its variance

Table 4. Overall mean and variance of the parental and mid-parental populations in deformation at first major peak (DFP) and maximum force (MF) from flesh puncture test in grapes.

\begin{tabular}{lccccc}
\hline & \multicolumn{2}{c}{ DFP } & & \multicolumn{2}{c}{ MF } \\
\cline { 2 - 3 } \cline { 5 - 6 } & Mean & Variance $^{z}$ & & Mean & Variance $^{z}$ \\
\hline Parenty & $0.4017^{z}$ & 0.0304 & & $-0.1450^{z}$ & 0.0139 \\
Mid-parent & $(2.52 \mathrm{~mm})$ & & & $(0.72 \mathrm{~N})$ & \\
& $0.4312^{\mathrm{z}}$ & 0.0172 & & $-0.1848^{\mathrm{z}}$ & 0.0054 \\
& $(2.70 \mathrm{~mm})$ & & & $(0.65 \mathrm{~N})$ & \\
\hline
\end{tabular}

${ }^{2} \log$ transformed value.

ySee Table 1.

Table 5. Analysis of variance for deformation at first major peak (DFP) and maximum force (MF) from flesh puncture test using $184 \mathrm{offspring}$ from 23 full-sib families in grapes. ${ }^{z}$

\begin{tabular}{lccccc}
\hline & \multicolumn{2}{c}{ DFP } & & \multicolumn{2}{c}{ MF } \\
\cline { 2 - 3 } \cline { 5 - 6 } $\begin{array}{l}\text { Source of } \\
\text { variation }\end{array}$ & $\begin{array}{c}\text { Sum of } \\
\text { squares }\end{array}$ & $\begin{array}{c}\text { Mean } \\
\text { squares }\end{array}$ & & $\begin{array}{c}\text { Sum of } \\
\text { squares }\end{array}$ & $\begin{array}{c}\text { Mean } \\
\text { squares }\end{array}$ \\
\hline Between-family & 2.4516 & $0.1114^{* *}$ & & 2.4628 & $0.1120^{* *}$ \\
Regression & 1.8418 & $1.8418^{* *}$ & & 0.8062 & $0.8062^{* *}$ \\
Residual & 0.6098 & 0.0290 & & 1.6566 & 0.0789 \\
Within-family & 3.4370 & 0.0213 & & 7.4480 & 0.0463 \\
Total & 5.8886 & & & 9.9108 & \\
\hline
\end{tabular}

${ }^{2}$ Data was analyzed after logarithmical transformation.

${ }^{* *}$ Significant at $P \leq 0.01$.
Table 6. Estimates of variance components obtained from the analysis of variance in deformation at first major peak (DFP) and maximum force (MF) tested from flesh puncture test using 184 offspring in 23 full-sib families in grapes. ${ }^{\mathrm{z}}$

\begin{tabular}{lll}
\hline & \multicolumn{2}{c}{ Estimates } \\
\cline { 2 - 3 } Variance components & \multicolumn{1}{c}{ DFP } & \multicolumn{1}{c}{ MF } \\
\hline Between-family $\left(\sigma^{2}{ }_{b f}\right)$ & $0.0113(35)^{\mathrm{z}}$ & $0.0082(16)^{\mathrm{z}}$ \\
Regression $\left(\sigma_{\mathrm{r}}^{2}\right)$ & $0.0103(32)$ & $0.0041(8)$ \\
Residual $\left(\sigma_{\mathrm{d}}^{2}\right)$ & $0.0010(3)$ & $0.0041(8)$ \\
Within-family $\left(\sigma^{2}{ }_{\mathrm{w}}\right)$ & $0.0213(65)$ & $0.0463(84)$ \\
Genetic $\left(\sigma^{2}{ }_{\mathrm{wg}}\right)$ & $0.0152(47)$ & $0.0349(64)$ \\
Environmental $\left(\sigma_{\mathrm{we}}^{2}\right)$ & $0.0061(18)$ & $0.0114(20)$ \\
Total & $0.0326(100)$ & $0.0545(100)$
\end{tabular}

zValues within parenthesis indicate the proportion to the total variance. $\sigma^{2}{ }_{w}=\sigma^{2}{ }_{w g}+\sigma^{2}{ }_{w e}$. ANOVA was performed after the data were transformed logarithmically.
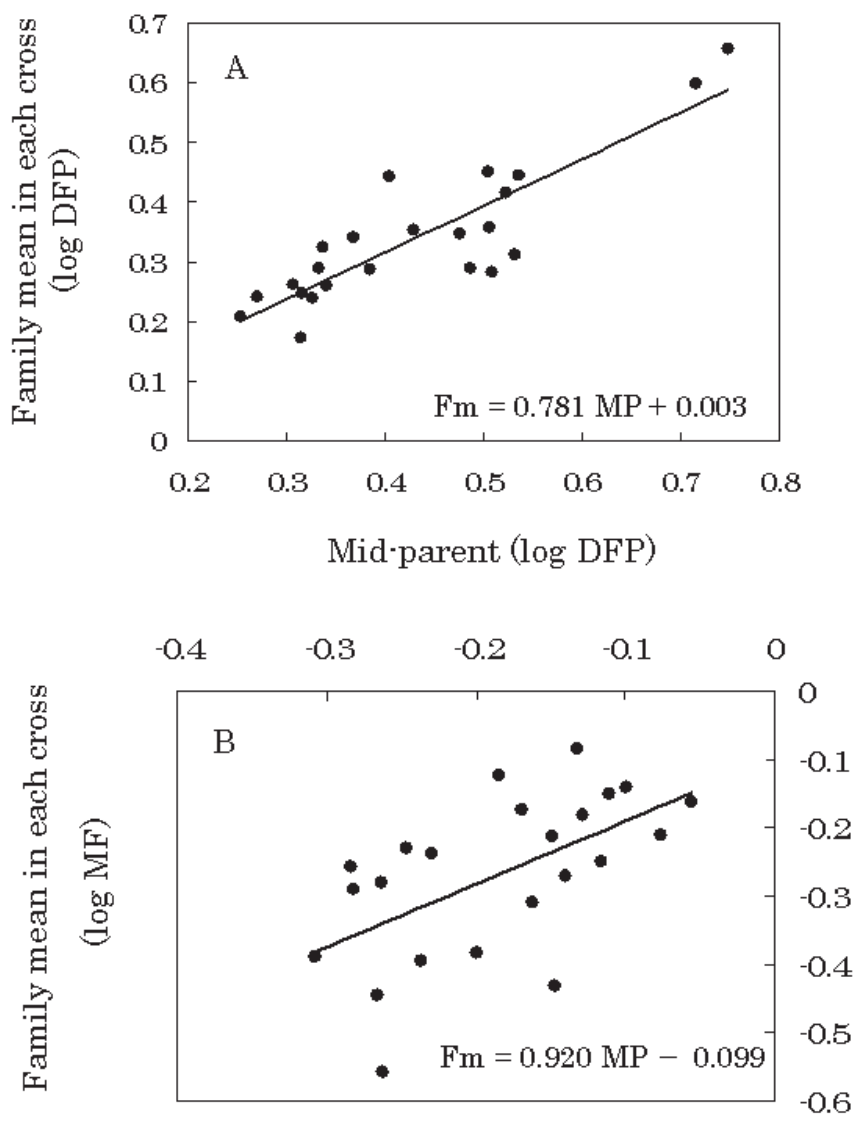

Mid-parent (log MF)

Fig. 2. Relationship between mid-parent (MP) and family mean (Fm) for deformation at first major peak (DFP) (A), and maximum force (MF) (B) from flesh puncture test in grapes. Each value represents the mean of eight offspring from each family. Five berries from a single vine were measured for each offspring without yearly repetition. Mid-parental values were based on measurements repeated for 3 years, using 20 berries from a single vine. 

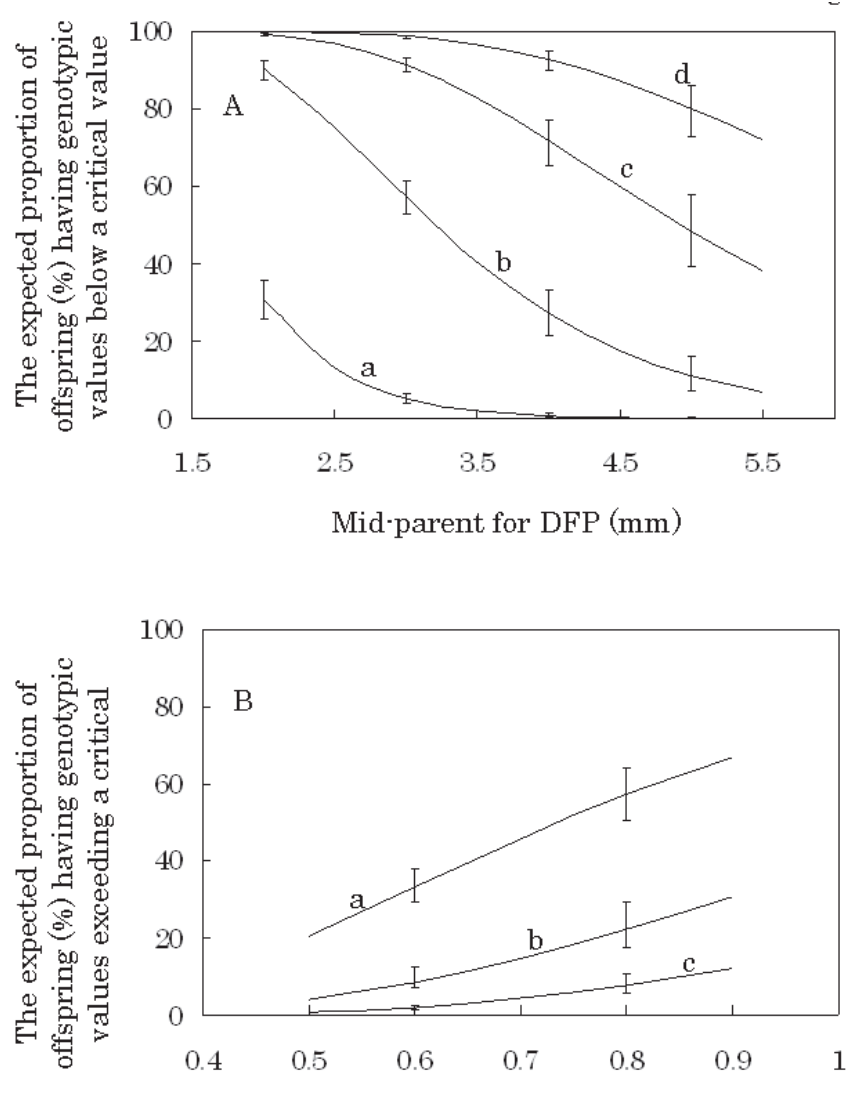

Mid-parent for MF (N)

Fig. 3. The expected proportion of offspring having genotypic value below a critical value for deformation at first major peak (DFP) (A) and exceeding a critical value for maximum force (MF) (B) from flesh puncture test in grapes. The expected proportions were predicted from mid-parental values which were based on measurements repeated for three years, using 20 berries from a single vine. Small alphabetical letters indicate a critical value in selection, $1.5 \mathrm{~mm}$ (a), $2.5 \mathrm{~mm}$ (b), $3.5 \mathrm{~mm}$ (c), and $4.5 \mathrm{~mm}$ (d) for DFP and $0.6 \mathrm{~N}$ (a), $0.9 \mathrm{~N} \mathrm{(b)}$, and $1.2 \mathrm{~N}$ (c) for MF, respectively. Vertical bars indicate the range of the EP in \pm SE points of family mean in a cross predicted by the regression.

in MP (0.0054) was less than half of that in the parental group $(0.0139) . \sigma_{\mathrm{MPG}}^{2}$ was 0.0036 , and the $\sigma_{\mathrm{MPG}}^{2} / \sigma_{\mathrm{MPP}}^{2}$ ratio was 0.67 , lower than in DFP. The overall mean MF of the offspring, -0.2685 $(\log 0.54 \mathrm{~N})$, was slightly smaller than that of the MP.

ANOVA revealed that the offspring population had small between-family and large within-family variance (Tables 5 and 6 ). The within-family variance $\left(\sigma^{2}\right)$ accounted for $84 \%$ of the total variance. Seventy-five percent of the within-family variance was genetic variance $\left(\sigma^{2}{ }_{w g}\right)$. The results indicated that the genetic variation in the offspring was not largely due to differences between families but, rather, to genetic differences within families.

The regression of Fm on MP was highly significant (Table 5); the equation obtained was Fm $=0.920 \mathrm{MP}-0.099$ (Fig. 2B). The $\mathrm{SE}$ of the regression coefficient was $\pm 0.288 . \sigma_{\mathrm{d}}^{2}(0.0041)$ was $50 \%$ of $\sigma_{b f}^{2}$, but accounted for only $9 \%$ of the genetic variance in the offspring population (the sum of $\sigma^{2}$ bf and $\sigma^{2}{ }_{\text {wg }}$ ) (Table 6). Consequently, the influence of $\sigma_{\mathrm{d}}^{2}$ was disregarded in the following analysis.

The EP of offspring having genotypic values exceeding a critical value $(0.9 \mathrm{~N})$ was calculated from the parental performance in five-berry samples from four clusters on a single vine with three annual repetitions (Fig. 3B). The EP of offspring having $\mathrm{MF}$ above $0.9 \mathrm{~N}$ increased as the MP values increased, i.e., $4 \%$ for $\mathrm{MP}=0.5 \mathrm{~N}, 15 \%$ for $\mathrm{MP}=0.7 \mathrm{~N}$, and $30 \%$ for $\mathrm{MP}=0.9 \mathrm{~N}$. The EP, however, was $<50 \%$ when the MP value was less than the critical value because the family mean estimated was less than the MP value.

EP OF OFFSPRING WITH CRISP TEXTURE. When the MP value for MF was $0.9 \mathrm{~N}$, the EP of offspring with crisp texture greatly decreased as the MP value for DFP increased (Fig. 4), ranging from $28 \%$ (MP for $\mathrm{DFP}=2.0 \mathrm{~mm}$ ) to $2 \%$ ( $\mathrm{MP}=5.5 \mathrm{~mm}$ ). Thus, 14 times as many offspring should be raised for MP $=5.5 \mathrm{~mm}$ in DFP than for MP $=2.0 \mathrm{~mm}$ to obtain offspring having crisp texture when the MP for MF is $0.9 \mathrm{~N}$. When the MP for MF was $0.5 \mathrm{~N}$, the $\mathrm{EP}$ was $<4 \%$. For MP $=0.7 \mathrm{~N} \mathrm{MF}$, the $\mathrm{EP}$ was $11 \%$ when DFP $=2.5 \mathrm{~mm}, 6 \%$ when DFP $=3.5 \mathrm{~mm}$, and $3 \%$ when $\mathrm{DFP}=4.5 \mathrm{~mm}$.

\section{Discussion}

Sato and Yamada (2003) measured DFP and MF in 62 V. vinifera and $25 \mathrm{~V}$. labruscana cultivars, and found wide species-dependent variation. The parental cultivars/selections in the present study (Table 4) had a mean DFP value $(2.52 \mathrm{~mm})$ close to that of $V$. vinifera table-use cultivars $(2.06 \mathrm{~mm})$ but smaller than that of the V. labruscana table-use cultivars studied before $(4.20 \mathrm{~mm}$; Sato and Yamada, 2003). However, the variance of DFP in the parental cultivars/selections [0.0304 (Table 4)] was larger than that of the $V$. vinifera table-use cultivars (0.017) and comparable to that of the V. labruscana table-use cultivars (0.034).

On the other hand, the variance of MF in the parental population [0.0139 (Table 4)] was only $27 \%$ of that in the V. vinifera table-use grape cultivars studied by Sato and Yamada (2003), while the mean value was similar to those of V. labruscana $(0.75$ $\mathrm{N}$ ) and $V$. vinifera table-use cultivars [0.82 N (Sato and Yamada, 2003)]. Thus, the parental cultivars/selections in the present study had a narrower genetic variation in MF than in DFP.

In the model, EP is influenced by 1) variation in mid-parental value, 2) regression, 3) within-family variation in offspring, and 4) critical value in selection (Yamada et al., 1997). While the critical value is based on breeding objectives, the other factors
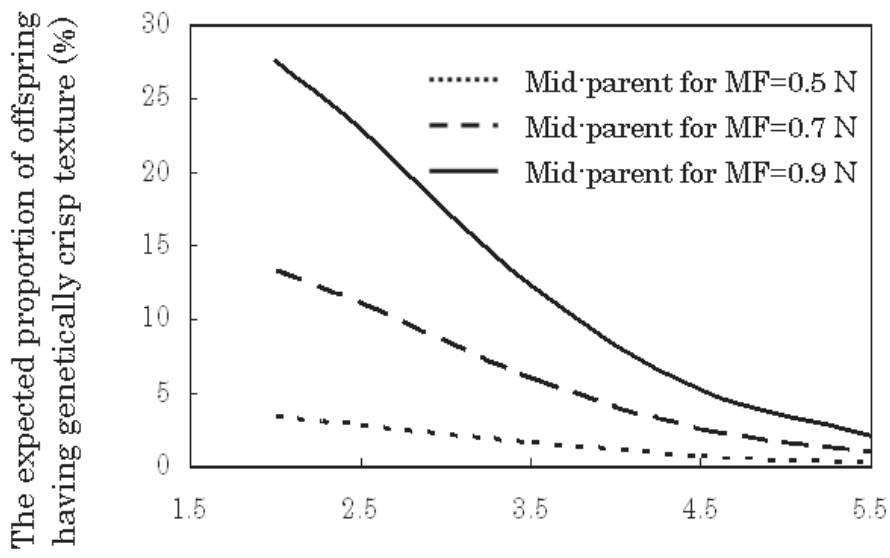

Mid-parent for DFP (mm)

Fig. 4. The expected proportion of offspring having genetically crisp texture [2.5 $\mathrm{mm} \geq$ deformation at first major peak (DFP), and $0.9 \mathrm{~N} \leq$ maximum force (MF)] from flesh puncture test in grapes. The expected proportions were predicted from mid-parental values which were based on measurements repeated for 3 years, using 20 berries from a single vine. 
are influenced by the population analyzed and the inheritance pattern of the trait. As for the population analyzed, there were differences between DFP and MF.

With respect to DFP, the parental and the MP populations were characterized by a small mean value and wide variation. The reason for the small mean DFP was that only a few hybrid cultivars/selections with large DFP(Akitsu 7, 'Buffalo', and 'North Red') and a relatively large number of $V$. vinifera cultivars/selections were used as parents (the crosses included 13 interspecific hybrid $\times V$. vinifera and four $V$. vinifera $\times V$. vinifera).

The phenotypic DFP variance in parents was comparable to that in the V. labruscana cultivar population studied by Sato and Yamada (2003). Although a high diversity of parental combinations were chosen for crossing, crosses showing DFPvalues in MP over $5 \mathrm{~mm}$ were rare (Fig. 2A) because the parental mean DFP in the present study was as small as the mean DFP of the $V$. vinifera cultivar group studied previously (Sato and Yamada, 2003).

The residual variance of the regression $\left(\sigma_{d}^{2}\right)$ in DFP accounted for only $9 \%$ of the between-family variance $\left(\sigma^{2}{ }_{b f}\right)$, indicating that the variation of DFP among family means could be mostly explained by the MP value. The small value of the ratio $\sigma^{2}{ }_{d} / \sigma^{2}{ }_{b f}$ led to an EP estimation with a small error in DFP. Generally, $\sigma_{d}^{2}$ is influenced by the environmental variance involved in the MP value and unknown factors such as dominance effect. The very high $\sigma^{2}{ }_{M P G} / \sigma^{2}$ MPP in DFP, an indicator of the degree of genetic determination of the MP value, showed that the environmental effect on MP value was small and that the 3-year's evaluation was sufficient to successfully determine the parental genotypic value of DFP.

Dominance effect tended to increase $\sigma^{2}$. However, the small $\sigma^{2}{ }_{d}$ value we found suggested negligible dominance effects in the population studied. Large genetic variation of MP, on the other hand, can reduce $\sigma_{\mathrm{d}}^{2} / \sigma^{2}$ bf , because it increases the between-family variance. In DFP, the small ratio $\sigma_{\mathrm{d}}^{2} / \sigma^{2}{ }_{\mathrm{bf}}$ resulted from three factors: 1) a high $\sigma^{2}{ }_{\mathrm{MPG}} / \sigma_{\mathrm{MPP}}^{2}$ ratio, 2) negligible dominance effects, and 3) wide genetic variation of MP.

As mentioned above, the parental and MP populations showed narrow variation in MF. The data in this study was obtained from the offspring of crosses which were made solely for the purpose of genetic improvement. In grape breeding, soft-fleshed parents are likely to be crossed with firm-fleshed ones because breeders aim to obtain firm-fleshed offspring. Thus, the narrow MP variation in MF might be due to the choice of parents in the breeding program.

$\sigma^{2}{ }_{d}$ accounted for $50 \%$ of the $\sigma^{2}$ bf for MF. As described above, $\sigma^{2}$ was influenced by the environmental variance of the MP value. The moderate $\sigma^{2}{ }_{\mathrm{MPG}} / \sigma^{2}{ }_{\mathrm{MPP}}$ value for $\mathrm{MF}(0.67)$ suggests that $\sigma^{2}$ would be reduced if repeated parental evaluations provided high $\sigma_{\text {MPG }}^{2} / \sigma_{\text {MPP }}^{2}$ value. It was also probable that the small MP variance in MF reduced $\sigma_{\text {bf }}^{2}$ and thus $\sigma^{2}{ }_{\mathrm{MPG}} / \sigma^{2}{ }_{\mathrm{MPP}}$ The small MP genetic variance also resulted in a high $\sigma^{2}{ }_{\mathrm{d}} / \sigma^{2}$ bf ratio. If parents were randomly selected from a population with a wide range of flesh firmness, the resultant wide MP variation would increase $\sigma^{2}$ bf. In addition, with respect to $\mathrm{MF}$, the population studied here was characterized by large within-family variance $\left(\sigma^{2}{ }_{w}\right)$ as compared to small $\sigma_{b f}^{2}$, and narrow MP variation. Therefore EP was not largely influenced by MP in this population. The same situation has previously been described in a study on soluble solids content of a japanese persimmon (Diospyros kaki Thunb.) breeding population (Yamada et al., 1997).

The EP for MF could be predicted with reasonable accuracy, because $\sigma^{2}$ accounted for only $9 \%$ of the total genetic variance in the offspring $\left(\sigma_{b f}^{2}+\sigma_{w g}^{2}\right)$. In this study, however, MP ranged only from 0.5 to $0.9 \mathrm{~N}$. To determine EP precisely when the MP value for MF is beyond this range, further genetic studies using parents having firmer or softer flesh are required. Since the mean value of DFP in MP population was small, the correlation between DFP and MF in the offspring population was weak $\left(r^{2}=0.05\right)$. Therefore, the EP of offspring having crispy flesh was estimated assuming that DFP and MF were independent of each other. In spite of weak correlation, the EP of offspring with crisp texture was low: only $12 \%$ when $\mathrm{DFP}=3.5 \mathrm{~mm}$ and $\mathrm{MF}=0.9 \mathrm{~N}$ in MP. The EP was further reduced to less only $5 \%$ if MP values of DFP were larger than $4.5 \mathrm{~mm}$ DFP. This indicated the difficulties in obtaining offspring with crispy flesh in interspecific breeding.

Interspecific hybridization of American species and $V$. vinifera began in the 19th century (Reisch and Pratt, 1996; Snyder, 1937). Some improved hybrid cultivars such as 'Jupiter' (Clark and Moore, 1999), 'Saturn' (Moore et al., 1989), and 'Remaily Seedless' (Pool et al., 1981), which had crisp or semi-crisp texture, had been produced by several cycles of selection among interspecific hybrid cultivars/selections. However, in the early stages of those breeding activities, it probably was difficult to obtain cultivars with crispy flesh. No interspecific hybrid cultivars with crispy flesh were described in the early literatures (Hedrick, 1908, 1925). The failure to obtain such cultivars may have been due partly to the fact that other trait such as muscat flavor and seedlessness were considered of prime importance (Slate et al., 1962; Wellington, 1937). However, the results in the present study suggest the difficulty to obtain offspring with crisp texture in the breeding using V. labruscana as parents, in which MP commonly has larger than $5 \mathrm{~mm}$ DFP.

The present study showed that the family mean of DFP was mostly determined by the DFP in MP. This indicated that selection over generations and backcrossing to $V$. vinifera [(V. labruscana $\mathrm{x} V$. vinifera) $\mathrm{x} V$. vinifera] may result in a certain percentage of offspring having small DFP and crisp texture. Recently, the NIFTS interspecific breeding program released two new diploid cultivars, 'Shine Muscat' (Yamada et al., 2004) and 'Oriental Star' (Yamada et al., 2005), both of which have crisp texture. However, since the objectives of interspecific breeding are to combine disease-resistance with fruit quality, it is desirable to cross interspecific hybrids to obtain disease-resistant offspring, rather than to backcross $V$. vinifera. Unfortunately, the present study suggests that the proportion of offspring having crisp texture that are obtained from crosses of interspecific cultivars/selections is considerably lower than that in the backcrosses.

Our results can be used also in the breeding of $V$. vinifera, which lacks cultivars having large DFP. Offspring having crisp texture can be readily obtained in crossing parents with small DFP, for example, 'Muscat of Alexandria' (2.04 mm for DFP and 1.05 $\mathrm{N}$ for MF), 'Cardinal' (1.42 mm and $0.94 \mathrm{~N}$ ), or 'July Muscat' (2.22 mm and 0.64 N) (Sato and Yamada, 2003). Crosses with MP values similar to those of 'Muscat of Alexandria', 'Cardinal', and 'July Muscat' are expected to yield 37\%, 33\%, and 9\% offspring with crisp texture, respectively. 


\section{Literature Cited}

Abbott, J.A., A.E. Watada, and D.R. Massie. 1984. Sensory and instrument measurement of apple texture. J. Amer. Soc. Hort. Sci. 109:221-228.

Alleweldt, G. and J.V. Possingham. 1988. Progress in grapevine breeding. Theor. Appl. Genet. 75:669-673.

Alleweldt, G., P. Spiegel-Roy, and B. Reisch. 1990. Grapes (Vitis). Acta Hort. 290:291-327.

Bailey, L.H. and E.Z. Bailey. 1930. Hortus. Macmillan, New York.

Bourne, M.C. 1966. Aclassification of objective methods for measuring texture and consistency of foods. J. Food Sci. 31:1011-1015.

Bourne, M.C. and N. Mondy. 1967. Measurement of whole potato firmness with a Universal testing machine. Food Technol. 21:13871406.

Bourne, M.C. 1979. Texture of temperate fruits. J. Texture Studies 10:25-44.

Brown, S.K. 1988. Assessment of fruit firmness in selected sour cherry genotypes. HortScience 23:882-884.

Campbell, R.C. 1974. Statistics for biologists 2nd ed. Baifukan, Tokyo.

Clark, J.R. and J. Moore. 1999. 'Jupiter' seedless grape. HortScience 34:1297-1299.

Einset, J. and C. Pratt. 1975. Grapes, p. 130-153. In: J. Janick and J.N. Moore (eds.). Advance in fruit breeding. Purdue Univ. Press, West Lafayette, Ind.

Friedman, H.H., J.E. Whitney, and A.S. Szczesniak. 1963. The Texturameter-A new instrument for objective texture measurement. J. Food. Sci. 28:390-396.

Galet, P. 1979. A practical ampelography. Cornell Univ. Press, Ithaca, N.Y.

Hedrick, U.P. 1908. Grapes of New York. J.B. Lyon Co., Albany, N.Y.

Hedrick, U.P. 1925. Systematic pomology. Macmillan, New York.

Lee, C.Y. and M.C. Bourne. 1980. Changes in grape firmness during maturation. J. Texture Studies 11:163-171.

Moore, J.N., J.R. Clark, and J.R. Morris. 1989. ‘Saturn' seedless grape. HortScience 24:861-862.

Pool, R.M., G. Remaily, B.I. Reisch, J.P. Watson, and K.H. Kimball. 1981. 'Remaily Seedless' grape. HortScience 16:232-233.

Reisch, B.I. and C. Pratt. 1996. Grapes, p. 297-369. In: J. Janick and J.N. Moore (eds.). Fruit breeding. Wiley, New York.

Sato, A., H. Yamane, N. Hirakawa, K. Otobe, and M. Yamada. 1997. Varietal differences in the texture of grape berries measured by penetration tests. Vitis 36:7-10.

Sato, A., M. Yamada, H. Iwanami, and N. Hirakawa. 2000. Optimal spatial and temporal measurements repetition for reducing environmental variation for berry traits in table grape breeding. Scientia Hort. 85:75-83.
Sato, A. and M. Yamada. 2003. Berry texture of table, wine, and dual purpose grape cultivars quantified. HortScience 38:578-581.

Slate, G.L., J. Watson, and J. Einset. 1962. Grape varieties introduced by the New York Agricultural Experiment Station, 1928-1961. Bul. 794.

Snedecor, G.W. and W.G. Cochran. 1972. Statistical methods, 6th ed. Iwanami Shoten, Tokyo.

Snyder, E. 1937. Grape development and improvement. p. 631-664. In: USDA Yrbk. Agr. 1937. Washington, D.C.

Weinberger, J.H. and F.N. Harmon. 1974. 'Flame seedless' grape. HortScience 9:602.

Wellington, R. 1937. Breeding hardy muscat grapes. Proc. Amer. Soc. Hort. Sci. 34:421-425.

Winkler, A.J. 1962. General viticulture. Univ. California Press, Berkeley, Calif.

Yamada, M., H. Yamane, K. Yoshinaga, and Y. Ukai. 1993. Optimal spatial and temporal measurement repetition for selection in japanese persimmon breeding. HortScience 28:838-841.

Yamada, M., H. Yamane, and Y. Ukai. 1994. Genetic analysis of japanese persimmon fruit weight. J. Amer. Soc. Hort. Sci. 119:1298-1302.

Yamada, M., H. Yamane, and Y. Ukai. 1995. Genetic analysis of fruit ripening time in japanese persimmon. J. Amer. Soc. Hort. Sci. 120:886-890.

Yamada, M., H. Yamane, Y. Takano, and Y. Ukai. 1997. Estimation of the proportion of offspring having soluble solids content in fruit exceeding a given critical value in japanese persimmon. Euphytica 93:119-126.

Yamada, M. and H. Yamane. 1997. Relationship between the observed and predicted distribution for fruit ripening time and fruit weight in japanese persimmon. Scientia Hort. 69:157-167.

Yamada, M., H. Yamane, A. Sato, N. Hirakawa, H. Iwanami, K. Yoshinaga, T. Ozawa, N. Mitani, M. Shiraishi, I. Nakajima, M. Nakano, and R. Nakaune. 2004. A new grape cultivar 'Shine Muscat'. J. Jpn. Soc. Hort. Sci. 73(Suppl.1):61. (Abstr.)

Yamada, M., A. Sato, H. Yamane, N. Hirakawa, H. Iwanami, N. Mitani, K. Yoshinaga, M. Shiraishi, T. Ozawa, M. Yoshioka, I. Nakajima, Y Sato, N. Mase, M. Nakano, and R. Nakaune. 2005. Anew grape cultivar 'Oriental Star'. J. Jpn. Soc. Hort. Sci. 74(Suppl.1):86. (Abstr.)

Yamane, H., A. Kurihara, K. Nagata, T. Kishi, M. Yamada, R. Matsumoto, T. Sumi, T. Hirabayashi, and K. Kanato, 1988. New grape cultivar 'Aki Seedless'. Bul. Fruit Tree Res. Sta. E7:1-8.

Yamane, H., A. Kurihara, M. Yamada, K. Nagata, K. Yoshinaga, R. Matsumoto, T. Ozawa, T. Sumi, T. Hirabayashi, and M. Kakutani, 1991. New grape cultivar 'North Red'. Bul. Fruit Tree Res. Sta. 20:41-48.

Yamane, H., A. Kurihara, M. Yamada, K. Nagata, K. Yoshinaga, R. Matsumoto, T. Ozawa, T. Sumi, T. Hirabayashi, M. Kakutani, and A. Sato. 1992. New grape cultivar 'North Black'. Bul. Fruit Tree Res. Sta. 20:41-48. 